\title{
2011 Dahlberg Award Winner: Evaluation of the utility of deciduous molar morphological variation in great ape phylogenetic analysis
}

Anna M. Hardin ${ }^{1,2}$ and Scott S. Legge ${ }^{1}$

${ }^{1}$ Macalester College, St Paul, Minnesota, 55105

2 University of Minnesota, Minneapolis, Minnesota, 55455

Keywords: primate deciduous dentition, non-metric dental traits, Pan, Gorilla

ABSTRACT Non-metric dental traits are wellestablished tools for anthropologists investigating population affiliation and movement in humans. Nonetheless, similar traits in the great apes have received considerably less attention. The present study provides data on non-metric trait variability in the deciduous molars of great apes from museum context.Twenty-eight traits are observed in the upper and lower deciduous molars in specimens of Pan troglodytes, Pan paniscus, Gorilla gorilla, and Gorilla beringei. These groups are compared based

The teeth of the great apes bear an uncanny resemblance to those of humans in terms of their overall morphology. While the permanent teeth of humans and great apes have been studied in depth for several decades, deciduous teeth are often overlooked. Unlike permanent teeth, which are often used in both metric and non-metric studies to trace genetic drift and population variation, deciduous teeth are rarely studied in detail or in large numbers in either humans or primates.

Since non-metric traits in adult primates have been used in many important studies they can serve as an example for work that can be done with deciduous primate teeth. Several studies offer trait frequency data for non-metric traits in great ape adult dentitions (e.g., Bailey 2008, Swindler 2005, Swarts 1988) and Swindler (2005) provides some description of the morphology of great ape deciduous teeth. Human deciduous dental morphology has been described by Jorgensen (1956) and Scott and Turner (1997).

The present study addresses the dearth of information on great ape deciduous dentitions by looking at the variation in tooth crown morphology of subadult chimpanzees and gorillas. Previous research on non-metric traits among humans has revealed that they are useful in assessing population relatedness as well as population movements through time (e.g. Scott and Turner, 1997; Irish, 2006; Hanihara, 2008), and analysis of the decidu- on trait frequencies and mean measures of divergence. This study demonstrates the variability of non-metric traits in the deciduous molars of chimpanzees and gorillas. These traits could potentially be used in the same way that non-metric traits are in humans, namely group affiliation and population movements through time. Further, this study establishes scoring guidelines and methodology relevant to deciduous dental morphological characteristics found in the great apes, but not necessarily in humans.

ous dentition of the great apes may allow for similar assessments. In this study, variations in frequencies and patterns of occurrence for 28 dental traits are examined in five great ape subspecies. The utility of the deciduous dentition is assessed in addressing questions of population affinity and contributing to a set of standards and traits that can be used in further studies.

\section{MATERIALS}

Data were collected on the postcanine deciduous teeth from detailed photographs of 179 juvenile great ape dental arcades. The specimens belong to the collections of the Quex Museum of Birchington, UK and the Royal Museum of Central Africa in Tervuren, Belgium. Five of the gorillas came from the collection at the University of Minnesota Department of Anthropology. The samples included specimens identified in the museum catalogs as Pan troglodytes troglodytes, Pan troglodytes schweinfurthii, Pan paniscus, Gorilla gorilla gorilla, and Gorilla beringei graueri (Table 1).

Correspondence to: Anna Hardin

University of Minnesota, Department of Anthropology

395 Humphrey Center, 301 19th Ave S.

Minneapolis, MN 55455

hardi227@umn.edu 319-321-7104 
TABLE 1. Number of individuals studied in each African ape group

\begin{tabular}{lcc}
\hline \multicolumn{1}{c}{ Species } & $\begin{array}{c}\text { Number of indi- } \\
\text { viduals }\end{array}$ & Number of teeth \\
\hline $\begin{array}{l}\text { Pan troglo- } \\
\text { dytes }\end{array}$ & 99 & 665 \\
$\begin{array}{l}\text { P. t. trog- } \\
\text { lodytes }\end{array}$ & 39 & 270 \\
$\begin{array}{l}\text { P. } \text { t. } \\
\text { schwein- } \\
\text { furthii }\end{array}$ & 60 & 395 \\
$\begin{array}{l}\text { Pan paniscus } \\
\text { Gorilla goril- }\end{array}$ & 48 & 329 \\
la gorilla & 28 & 194 \\
$\begin{array}{l}\text { Gorilla ber- } \\
\text { ingei graueri }\end{array}$ & 11 & 81 \\
\hline
\end{tabular}

\section{METHODS}

\section{Traits}

Upper deciduous molars. Nine traits were observed in the upper deciduous molars. The transverse crest in the upper first deciduous molar (udp3) is an enamel ridge connecting the paracone and protocone (Swindler, 2005). It has been variously labeled the central ridge (Jørgensen, 1956) and the oblique ridge (Kraus et al. 1969) in human deciduous teeth. For the present study it was scored according to a previously used scale from 0 to 3 (Bailey, 2002). Although this scoring was originally for lower adult premolars, it describes the variation in udp3 well.

The lingual cingulum of the two upper deciduous molars (udp3 and udp4) was scored from 0 to 3 (Figure 1). The scores are based on Swindler's observation that the lingual cingulum in Gorilla and Pan differed in that, "A lingual cingulum is present in Gorilla extending mesially from the hypocone to the mesial surface of the protocone. A cingulum is present in Pan only on the lingual surface of the protocone." (Swindler, 2005). Due to these distinctions, this trait was scored as absent (0), a raised surface of the lingual side of the protocone (1), an enamel ridge on the lingual side of the protocone (2), or an enamel ridge extending from the protocone to the hypocone (3). On udp3 there is no hypocone, so the scoring of 3 is reserved for a lingual cingulum that extends across the entire lingual surface of the protocone. It is important to note that the smallest lingual cingulum is not considered to be a small Carabelli's trait because these two structures likely derive from separate features (Ortiz et al. , 2010). The buccal cingulum on udp3 and udp4 is scored only as present or absent where presence is considered to be any expression of a cingulum on the buccal surface of the tooth (Figure 2). None of the sources that were used mentioned a buccal cingulum on the great ape upper deciduous dentition, although it is observed in the great apes on lower deciduous molars and upper permanent molars (Swindler, 2005).

The crista obliqua is a ridge connecting the protocone and metacone of udp4 (Swindler, 2005). It has also been referred to as the postprotocrista (Swarts, 1988). It was recorded as absent (0), inter-

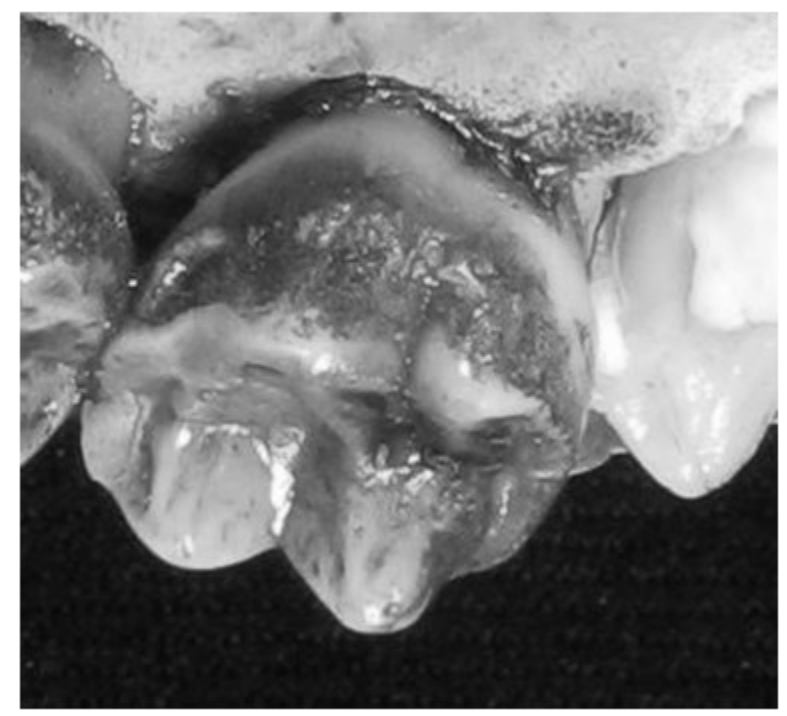

Fig. 1. Complete lingual cingulum on udp4 scored as 3 .

rupted (1) or uninterrupted (2). Also on udp4, cusp 5 was scored from 0 to 5 following the Arizona State University Dental Anthropology System (ASUDAS) for cusp 5 on UM1 (Turner et al. 1991). Finally, the anterior and posterior foveae on udp4 were scored as either present or absent. In the ASUDAS, the anterior fovea is scored based on its size, but the present study found that on deciduous teeth both anterior and posterior foveae were generally too small to vary noticeably. Any 


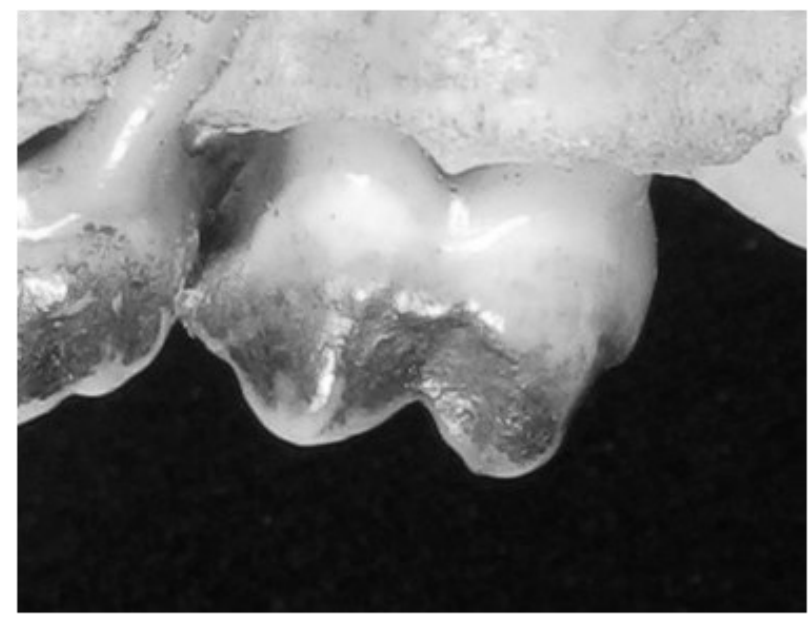

Fig. 2. Buccal cingulum on udp4 scored as present.

visible pit or fovea along the mesial or distal marginal ridge of the tooth was scored as an anterior or posterior fovea respectively.

Lower deciduous molars. Scores for 19 traits on the lower deciduous dentition were recorded for this study. The first takes note of the presence or absence of the metaconid on the lower first deciduous molar (ldp3) and its placement relative to the protoconid. The placement of the metaconid relative to the protoconid has been described both as variable in the permanent lower first and second premolars (LP3 and LP4) of Pan (Bailey, 2008) and as distal to the protoconid in ldp3 in the great apes (Swindler, 2005). Jørgensen (1956) also describes the distal metaconid in human deciduous teeth, but mentions that in the great apes the metaconid may be "faint or absent." Based on these reports and early observations, metaconids were scored in this study as absent (0), mesial to the protoconid (1), central to the protoconid (2) or distal to the protoconid (3). Based on Ludwig's (1957) description of the metaconid based on where it sits relative to "the long axis of the median ridge of the buccal cusp," the metaconid is scored as distal if the majority of the metaconid is distal to the median ridge of the protoconid, On the other hand, if the metaconid appears to sit directly on the axis of the median ridge of the protoconid then it is considered central.

The entoconid, hypoconid and hypoconulid are also scored on ldp3 and ldp4. The entoconid and hypoconid were scored as either present or absent and the hypoconulid was scored according to the ASUDAS from 0 to 5 with an additional val- ue denoting a hypoconulid that was clearly present but could not be sized due to heavy wear (7).

The mid-trigonid crest is an enamel ridge on ldp4 that connects the protoconid and metaconid (Figure 3). It is mesial to the distal trigonid crest that connects the same cusps. The mid-trigonid crest may also be called a complete bridge formed by the mesial accessory ridges of the protoconid and metaconid (Hooijer, 1948; Scott and Turner, 1997), or the anterior transverse ridge (Jørgensen, 1956). Although there is an ASUDAS scoring plaque for this trait, the present study used a modified form of a scoring system presented by Bailey (2002) that better fit the variation found in great ape deciduous molars. The mid-trigonid crest was scored based on the absence of a crest (0), the presence of two accessory ridges that did not coalesce to form a crest (1), the presence of a crest interrupted by a mesio-distal groove (2), or the presence of an uninterrupted crest (3). The presence of the anterior fovea on ldp4 was dependent on the presence of the mid-trigonid crest, because without a crest between the anterior fovea and the trigonid basin, the two are indistinguishably joined. The distal trigonid crest sits distal to the mid-trigonid crest, connecting the more distal portions of the protoconid and metaconid (Figure 3). Scott and Turner (1997) call it the distal trigonid crest, but it has also been referred to as an extension of the distal accessory ridges of the protoconid and metaconid (Scott and Turner, 1997), the posterior trigonid crest (Weidenreich, 1937), the oblique crest (Jørgensen, 1956), or the transverse crest (Jørgensen, 1956). When the mid-trigonid crest is absent and there is only one crest connecting the protoconid and metaconid it is still called the distal trigonid crest in the present study, but it may be called the protocristid elsewhere (Swindler, 2005). The distal trigonid crest was scored in the same manner as the mid-trigonid crest.

The deflecting wrinkle in ldp4 is an enamel extension that goes buccally from the metaconid and then curves distally. This trait was ranked according to the ASUDAS as absent (0), weak (1), moderate (2), or marked (3).

There are several traits that involve either the division of existing cusps into multiple elements or the overall number of cusps on the teeth. Both the hypoconulid, following Jørgensen's (1956) ob- 


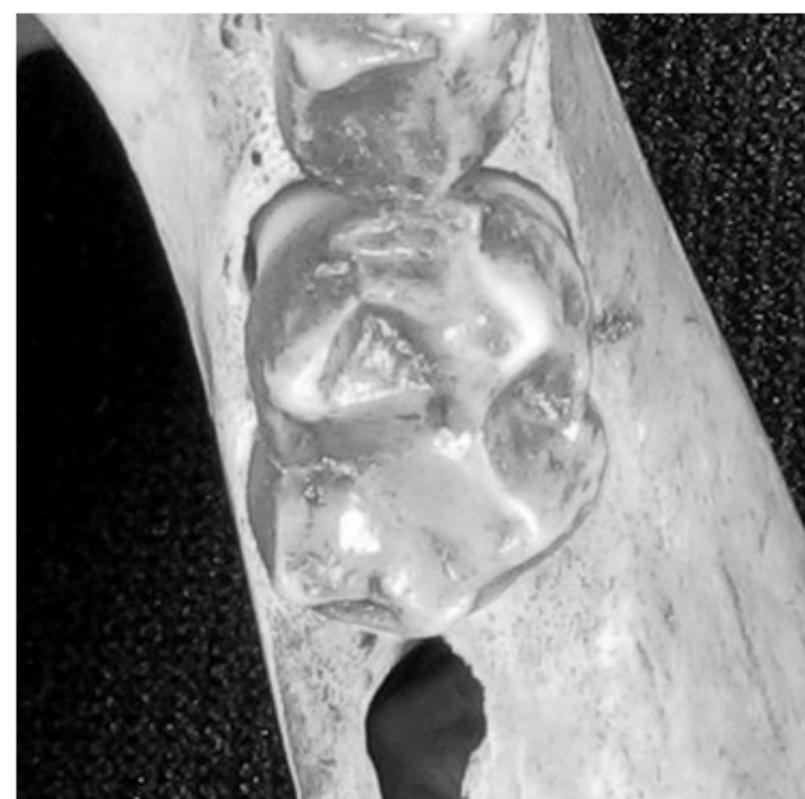

Fig. 3. Mid-trigonid and distal trigonid crests both scored as 3 .

servations of ldp4 in humans, and the entoconid were examined for a division in the cusp. These were each scored as either present or absent. The protostylid coming off of the disto-buccal edge of the protoconid on ldp4 was scored from 0 to 7 following the ASUDAS. The expression of cusp 6 on ldp4 appears as a cusp on the distal margin of the tooth between the hypoconulid and the entoconid. This trait was ranked from 0 to 5 with the ASUDAS. It may be important to note that a small cusp 6 may resemble a divided hypoconulid but that a divided cusp should have a single split apex while a cusp 6 will have its own apex distinct from the apex of the hypoconulid. Additionally, cusp 7 appears as a small cusp on the lingual margin of ldp4 between the metaconid and entoconid. It was scored using the ASUDAS from 0 to 5 as well.

Fissure pattern was observed in ldp4 and was scored as $\mathrm{Y},+$ or $\mathrm{X}$ according to definitions given by Scott and Turner (1997). As stated previously, the anterior fovea on ldp4 is a depression between the mesial marginal ridge and the mid-trigonid crest. It was scored as either present or absent. The posterior fovea was scored differently, however, because it was often more observable than the anterior or posterior foveae on udp4. This allowed it be scored as absent (0), a pit (1) or a fovea (2), where a pit is a depression bordered by the distal marginal ridge and a fovea is a depression that interrupts the distal marginal ridge.

\section{ANALYSIS}

For statistical analysis the traits were dichotomized using threshold values such that all traits were converted to either presence or absence. Table 2 includes the list of traits and their thresholds for presence. Following Turner et al. (1991), any occurrence of a trait in an individual was counted as presence, even if occurrence was unilateral. This way, traits were analyzed according to the number of individuals as opposed to the number of teeth. Metaconid placement and fissure pattern could not be converted to this form for analysis. These two traits were left in their original state and were analyzed by tooth instead of by individual. Frequencies of occurrence for each trait were compared between pairs of groups using Fisher's exact test. Analysis among the groups was conducted using the chi-square test. Both analyses were done using PASW Statistics 18.0. Phenetic distance among the groups was then assessed using Irish's (2010) adaptation of C.A.B. Smith's (1977) mean measure of divergence (MMD) formula.

In order to further study the relatedness of the sample groups, the mean measures of divergence for pair-wise comparisons of the five groups were computed. First Kendall's tau-B test was used to find any correlated traits. Out of the twenty-six dichotomized traits, four (udp3 lingual cingulum with udp4 lingual cingulum and ldp4 anterior fovea with ldp4 mid-trigonid crest) were correlated and four (ldp3 cusp 5, ldp4 entoconid, ldp4 hypoconid, and ldp4 hypoconulid division) were invariable (i.e. fixed as either all present or all absent) and therefore correlated with all of the other traits. All of the invariable traits and half of the correlated traits were removed, since without their related traits the other two would be uncorrelated. The lingual cingulum on udp4 was kept, since it showed greater variation than udp3 lingual cingulum, and ldp4 mid-trigonid crest was chosen instead of the ldp4 anterior fovea, since the presence of an anterior fovea is dependent on the presence of a mid-trigonid crest. Metaconid position on ldp3 and fissure pattern on ldp4 could not be used for the MMD analysis since these traits were not expressed through presence or absence, so metaconid position was converted for analysis and fissure pattern was excluded. The 21 remaining traits were then used for MMD calculations using the Freeman and Tukey transformation for small sam- 
ple size. The final equation for the mean measure of divergence was (Irish, 2010):

$$
\mathrm{MMD}=\sum_{i=1}^{\mathrm{r}} \frac{\left(\Theta_{1 i}-\Theta_{2 i}\right)^{2}-\left(1 /\left(\mathrm{n}_{1 i}+1 / 2\right)+1 /\left(\mathrm{n}_{2 i}+1 / 2\right)\right)}{\mathrm{r}}
$$

where $\mathrm{r}$ represents the number of uncorrelated traits, $\Theta$ denotes the angular transformation, which was calculated as:

$$
\Theta=(1 / 2) \sin ^{-1}(1-(2 \mathrm{k}) /(\mathrm{n}+1))+(1 / 2) \sin ^{-1}(1-2(\mathrm{k}+1) /
$$

$I$ represents the trait, $\mathrm{n}$ represents the number of individuals examined for the trait, and $\mathrm{k}$ represents the number of individuals for whom the trait was present. The MMD was calculated for pair-wise comparisons of each group (Table 3 ).

In order to test the significance of the MMDs the variance of each pair-wise comparison was calculated using:

$$
\operatorname{var}(\mathrm{MMD})=2 \sum_{i=1}^{\mathrm{r}} \frac{\left(1 /\left(\mathrm{n}_{1 i}+1 / 2\right)+1 /\left(\mathrm{n}_{2 i}+1 / 2\right)\right)^{2}}{\mathrm{r}^{2}}
$$

The square root of this $\operatorname{var}(\mathrm{MMD})$ value is the equivalent of the standard deviation, and if the MMD > $2 \mathrm{x} \sqrt{ } \operatorname{var}(\mathrm{MMD})$, the null hypothesis that the proportion of occurrence in sample 1 is equal to the proportion of occurrence in sample 2 is rejected at the 0.025 level (Harris and Sjøvold, 2004; Irish, 2010).

\section{RESULTS}

\section{Frequency Analysis}

Frequencies of each trait in all groups are listed in Table 2. There was no difference in trait frequencies between males and females in any group, so both sexes were pooled for all analyses. There were several traits that showed statistically significant differences between the various subspecies, species, and genera that were studied.

There are five traits that are significantly different between $P$. t. troglodytes and P. t. schweinfurthii (Table $2)$. This is a surprisingly large number of differences since they are very closely related. Compared to these two subspecies of chimpanzee G. g. gorilla and G. $b$. graueri, which belong to two different species, also had five traits with significant differences. However, the low variability in gorilla trait frequencies may be a result of sample size differences. The differences between the two Gorilla species are less likely to appear statistically significant because there are so many fewer cases studied. There are six traits that exhibit significant dif- ferences in frequency between $P$. troglodytes and $P$. paniscus. Between Pan and Gorilla eleven traits were found that varied significantly. This is the most variability shown between any of the groups and likely reflects the fact that these genera are the most distantly related of any of the groups studied.

\section{Mean Measure of Divergence}

All of the pair-wise comparisons between the primate groups are significant, but the value of these findings is unclear since they demonstrate that G. g. gorilla is more similar to $P$. paniscus than to $G$. b. graueri when they are otherwise morphologically dissimilar. The fact that these values show that there is variation between the groups is, at the moment, more important than how much the groups vary and in what ways. The differences show that there is significant variation in the deciduous molars of chimpanzees, bonobos and gorillas that is comparable to variation found in the adult dentition. Therefore, the deciduous dentition does show potential to be used similarly to adult dentition in research of ape population movement and genetic drift.

\section{DISCUSSION AND CONCLUSIONS}

The data presented above support several findings of past researchers regarding morphological characteristics, with some exceptions. As observed by Swindler (2005), there were no observable fifth cusps on ldp3 and all observable teeth exhibited the $\mathrm{Y}$ fissure pattern. However, lingual and buccal cingula in the upper dentition were present far more often than was described in the past (Swindler, 2005). Additionally, there are similarities seen between traits of primate adult and deciduous dentition. For example, cusp 6 on ldp4 and the lower first adult molar (LM1) seems to be expressed in $P$. troglodytes but not in P. paniscus (Bailey, 2008; Swindler, 2005). Cusp 6 is observed on LM1 in $16.2 \%$ of $P$. t. troglodytes and $2.3 \%$ of $P$. t. schweinfurthii, but none are observed in P. paniscus (Bailey, 2008), while on ldp4 cusp 6 was found in $23.5 \%$ of $P$. t. troglodytes and $24.2 \%$ of $P$. $t$. schweinfurthii and not at all in $P$. paniscus. Cusp 7 on the same tooth is expressed in $9.1 \%$ of adult $P$. paniscus (Bailey, 2008) and in $8.3 \%$ of juvenile $P$. paniscus and it is present in Gorilla, but it appears in neither adult nor juvenile $P$. troglodytes (Bailey, 2008; Swindler, 2005).

The results of MMD analysis are of particular interest when they are compared with another MMD analysis of similar non-metric dental traits in adult Pan (Bailey, 2008). Although the two data sets are quite different, there are some important similarities. Similar to Bailey's findings, we find 


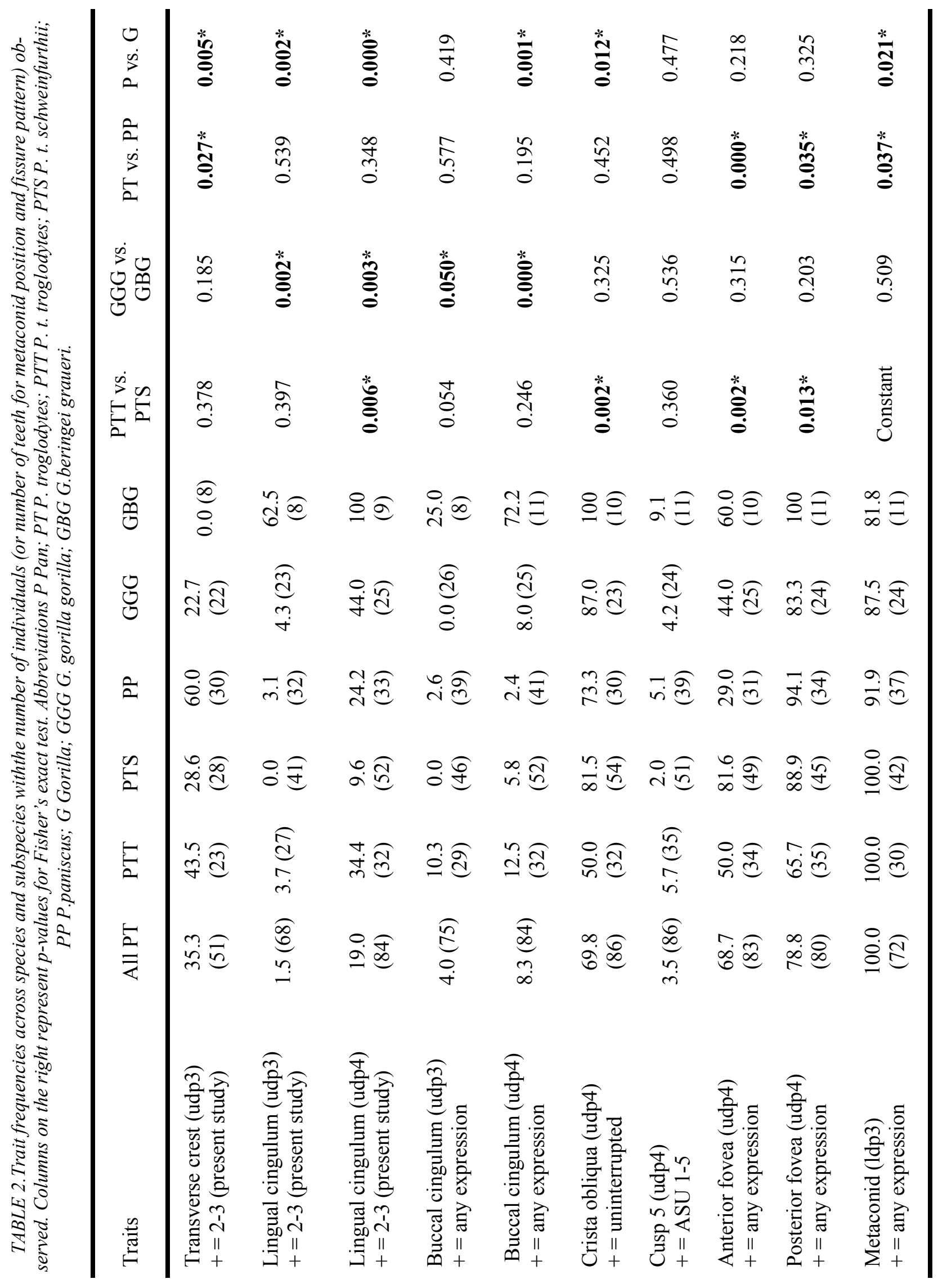




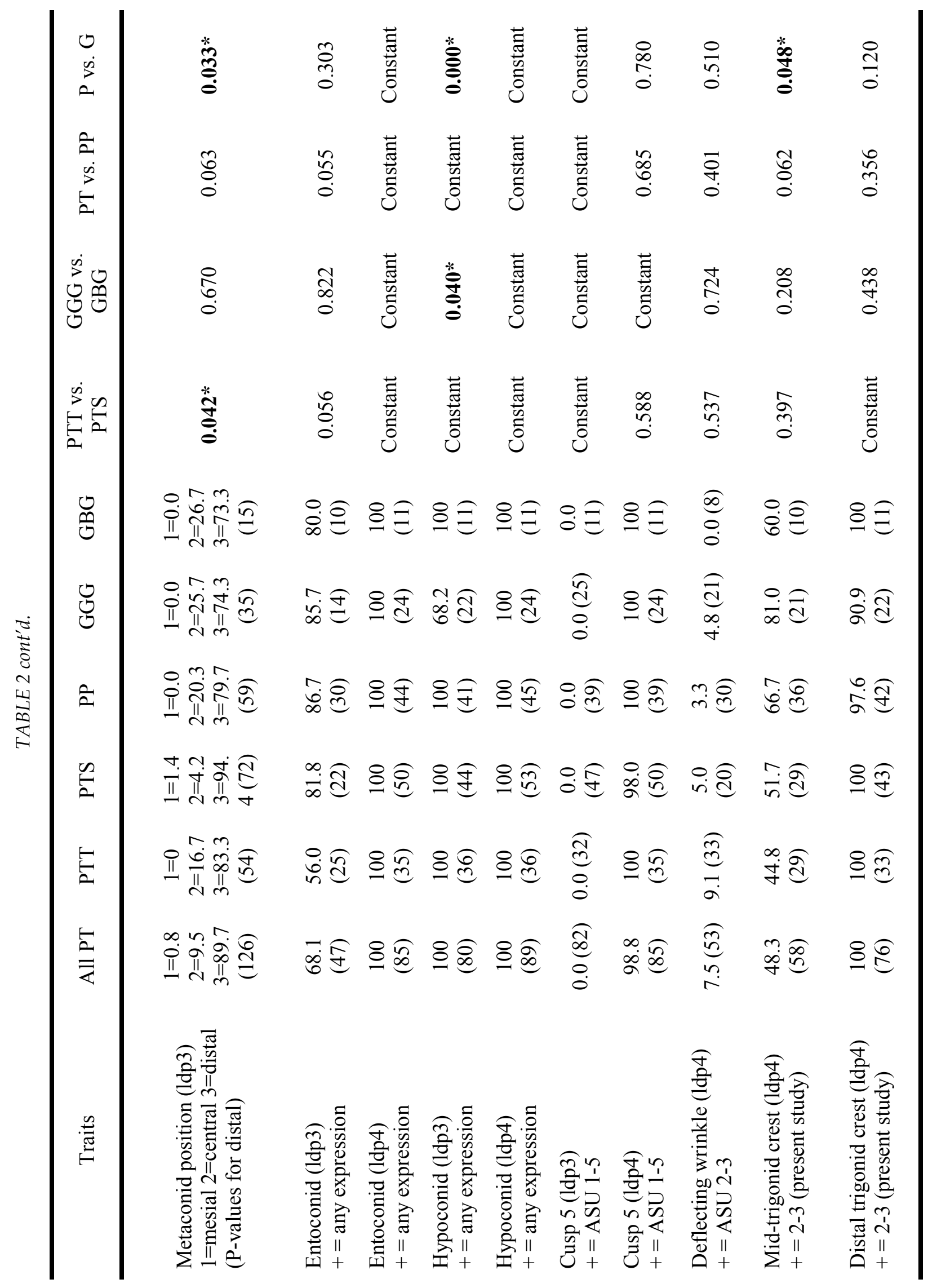




\begin{tabular}{|c|c|c|c|c|c|c|c|c|}
\hline $\begin{array}{l}0 \\
\dot{D} \\
\dot{D}\end{array}$ & 苞 & 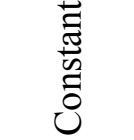 & 节 &  & \begin{tabular}{l}
$\infty$ \\
\multirow{0}{0}{} \\
$\dot{0}$
\end{tabular} & $\frac{\bar{N}}{0}$ & $\stackrel{\infty}{\stackrel{0}{0}}$ & 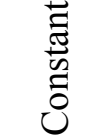 \\
\hline$\stackrel{\dot{n}}{\vec{n}} \hat{a}$ & 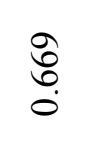 & 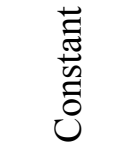 & $\frac{0}{3}$ &  & ฮั่ & ְ̊. & ¿̊ & $\begin{array}{l}\vec{\Xi} \\
\text { İ } \\
\tilde{0} \\
\tilde{0}\end{array}$ \\
\hline $\begin{array}{l}0 \\
0 \\
\dot{0} \\
\dot{D} \\
0\end{array}$ & $\stackrel{\overrightarrow{1}}{\dot{0}}$ & 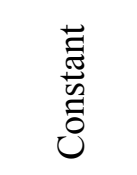 & 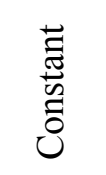 & $\begin{array}{l}\hat{\sigma} \\
0 \\
0\end{array}$ & $\frac{ \pm}{n}$ & రิ & 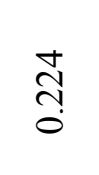 & 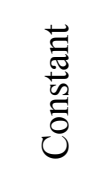 \\
\hline 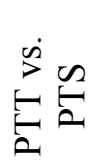 & $\begin{array}{l}n \\
n \\
0\end{array}$ & 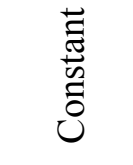 & 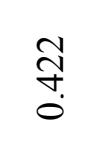 & $\begin{array}{l}\text { तु } \\
\text { : }\end{array}$ & 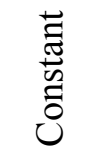 & ڤે & $\stackrel{1}{0}$ & 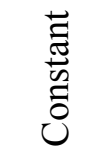 \\
\hline O & $8 \Xi$ & $\stackrel{0}{0} \Xi$ & $\stackrel{0}{0} \Xi$ & $\stackrel{0}{0} \Xi$ & $\vec{a} \cong$ & $\stackrel{0}{\circ} \stackrel{0}{ }$ & $\stackrel{\circ}{\dot{+}} \stackrel{0}{=}$ & $8 \overparen{త}$ \\
\hline ني & 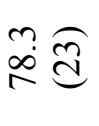 & $\begin{array}{l}\widehat{\vec{d}} \\
\stackrel{0}{0} \\
0\end{array}$ & $\begin{array}{l}\overparen{\approx} \\
0 \\
0\end{array}$ & $\begin{array}{l}\overparen{\Xi} \\
\underset{+}{\tau}\end{array}$ & $\begin{array}{l}\underset{f}{d} \\
0 \\
0\end{array}$ & 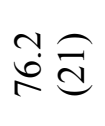 & $\stackrel{a}{\vec{b}}$ & 8 每 \\
\hline$\frac{a}{2}$ & $\stackrel{0}{0}$ & $\stackrel{0}{0} \Xi$ & $\begin{array}{l}0 \\
0 \\
0\end{array}$ & 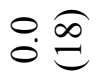 & $\begin{array}{l}n \\
\infty\end{array}$ & $\stackrel{0}{\circ} \tilde{8}$ & 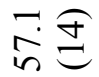 & 80 \\
\hline$\stackrel{\Omega}{\omega}$ & $\stackrel{n}{i} \underset{f}{\stackrel{f}{ \pm}}$ & $\stackrel{\overbrace{}}{\circ}$ & $\stackrel{n}{\stackrel{\tilde{J}}{巳}}$ & 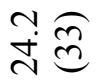 & $\stackrel{\overbrace{}}{\circ}$ & 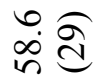 & î & $8 \widehat{0}$ \\
\hline$\stackrel{E}{E}$ & $\begin{array}{l}\text { ñ } \\
\stackrel{0}{0} \\
0 \\
0\end{array}$ & $\begin{array}{l}\sqrt{n} \\
\stackrel{0}{0} \\
0 \\
0\end{array}$ & $\begin{array}{l}\tilde{n} \\
\stackrel{n}{n} \\
i\end{array}$ & 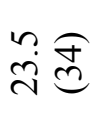 & $\begin{array}{l}\text { हn } \\
\stackrel{0}{0} \\
0 \\
0\end{array}$ & 穴 & 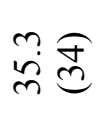 & $8 \overparen{f}$ \\
\hline$\stackrel{\text { 占 }}{\bar{E}}$ & 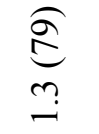 & $\begin{array}{l}\hat{\sigma} \\
0 \\
0\end{array}$ & $\begin{array}{l}\underset{\infty}{\infty} \\
\infty \\
\dot{n}\end{array}$ & $\ddot{\vartheta} \widehat{\widehat{\theta}}$ & $\begin{array}{l}\overparen{尺} \\
\stackrel{0}{0}\end{array}$ &  & 항 & 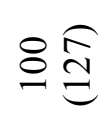 \\
\hline 营 & 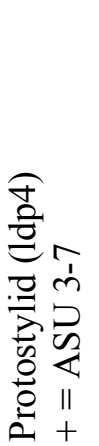 & 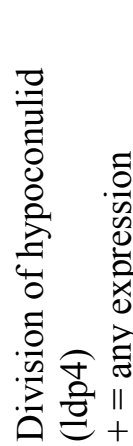 & 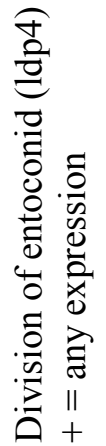 & 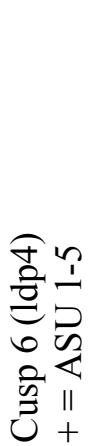 & 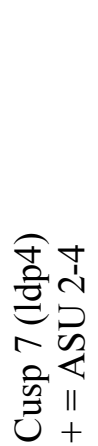 & 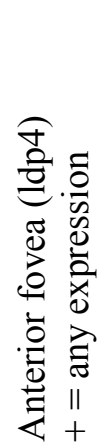 & 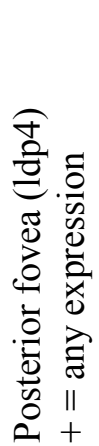 & 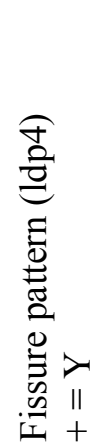 \\
\hline
\end{tabular}


that $P$. paniscus is more similar to $P$. $t$. schweinfurthii than it is to P. t. troglodytes. We also found that the two P. troglodytes subspecies are more similar to each other than either is to $P$. paniscus, which fits with Bailey's data (2008) and the substantial genetic and morphological evidence that indicates that the two $P$. troglodytes subspecies are more closely related to each other than to $P$. paniscus. There are also several unexpected similarities between the deciduous teeth of $P$. paniscus and G. g. gorilla. MMD analysis indicates that G..g. gorilla is more similar to P. paniscus than it is to the other Gorilla species or P. troglodytes. However, since researchers overwhelmingly conclude that G..g. gorilla is more closely related to other groups within the Gorilla genus than to the Pan genus, we assume that these similarities are due primarily to chance and not to a genetic closeness between the two very different species. The point here is that while the data do not give an entirely accurate view of how these subspecies and species are related, they can show that these groups display significant variation in their deciduous dental traits and that future research could perhaps give a more accurate estimation of those differences.

It is important to note the size of the samples used in this study. While our numbers of individuals observed were similar to those of Bailey (2008) for Pan, the number of observable samples of each trait is substantially lower, and for many important traits Bailey uses more observable samples. While it would clearly be helpful to have data on more deciduous teeth, it would also be useful to have more data on adult teeth to compare with this study to show more concretely whether deciduous teeth exhibit the same patterns as adult teeth. By using many traits across a larger variety of teeth, studies in the future will be able to produce more reliable data on the deciduous primate dentition.

\section{ACKNOWLEDGEMENTS}

Financial support was provided by the Paul Anderson Interdisciplinary Summer Research Fund and Macalester College. We would like to thank John Soderberg and Martha Tappen at the University of Minnesota, Wim Wendelen and Emmanuel Gilissen at the Royal Museum of Central Africa, and Angela Gill and Malcolm Harman at the Quex Museum House and Gardens for access to their primate skeletal collections. Finally special thanks to Brad Belbas at Macalester College for database interface creation, Chris Schmidt, and our two anonymous reviewers.

\section{LITERATURE CITED}

Bailey SE. 2002. A closer look at Neanderthal post canine dental morphology: The mandibular dentition. Anat Rec 269:148-156.

Bailey SE. 2008. Inter- and intra-specific variation in Pan tooth crown morphology: implications for Neandertal taxonomy. In: Irish JD, Nelson GC, editors. Technique and Application in Den tal Anthropology Cambridge: Cambridge University Press. p 293-316.

Hanihara T. 2008. Morphological variation of major human populations based on nonmetric dental traits. Am J Phys Anthropol 136:169-182.

Harris EF, Sjøvold T. 2004. Calculation of Smith's mean measure of divergence for intergroup comparisons using nonmetric data. Dent Anthropol 17:83-93.

TABLE 3. Mean measure of divergence values (with variance values) for pair-wise comparison of the five African ape groups. Abbreviations described in Table 2

\begin{tabular}{cccccc}
\hline & PTT & PTS & PP & GGG & GBG \\
\hline PTT & - & $0.074(0.02)$ & $0.099(0.02)$ & $0.328(0.02)$ & $0.806(0.04)$ \\
PTS & & - & $0.102(0.02)$ & $0.270(0.02)$ & $0.935(0.04)$ \\
PP & & & - & $0.243(0.02)$ & $0.733(0.04)$ \\
GGG & & & & - & $0.456(0.04)$ \\
GBG & & & & & -
\end{tabular}


Hooijer DA. 1948. Prehistoric teeth of man and of the orang-utan from Central Sumatra, with notes on the fossil orang-utan from Java and Southern China. Zoologische Mededelingen 29:175-301.

Irish JD. 2006. Who were the ancient Egyptians? Dental affinities among Neolithic through post dynastic peoples. Am J Phys Anthropol 129:529543.

Irish JD. 2010. The mean measure of divergence: Its utility in model-free and model-bound analyses relative to the Mahalanobis $D^{2}$ distance for nonmetric traits. Am J Hum Biol 22:378-395.

Jørgensen KD. 1956. The Deciduous Dentition: A descriptive and comparative anatomical study. Acta Odontol Scand 14:1-235.

Kraus BS, Jordan RE, Abrams L. 1969. Dental anat omy and occlusion; a study of the masticatory system. Baltimore: Williams and Wilkins.

Ludwig FJ. 1957. The Mandibular Second Premolars: Morphologic Variation and Inheritance. Journal of Dental Research 36:263-273.

Ortiz A, Skinner MM, Bailey SE, Hublin JJ. 2010. Carabelli's trait expression at the enamel-dentin junction (EDJ) and outer enamel surface (OES) of Pan maxillary molars. Am J Phys Anthropol 141:182-183.

Scott GR, Turner CG II. 1997. The anthropology of modern human teeth: dental morphology and its variation in recent human populations. Cambridge; New York: Cambridge University Press.

Smith CAB. 1977. A note on genetic distance. Ann Hum Genet 40(4):463-479

Swarts JD. 1988. Deciduous dentition: implications for hominoid phylogeny. In: Schwartz JH, editor. Orang-utan Biology. New York: Oxford University Press. p 263-270.

Swindler DR. 2005. Primate dentition: An introduction to the teeth of non human primates. Cambridge: Cambridge University Press.

Turner CG II, Nichol C, Scott GR. 1991. Scoring Procedures for Key Morphological Traits of the Permanent Dentition: the Arizona State University Dental Anthropology System. In: Kelley MA, Larsen CS, editors. Advances in Dental Anthropology. New York: Wiley-Liss. p 13-31.

Weidenreich F. 1937. The dentition of Sinanthropus pekinensis: a comparative odontography of the hominids. Palaeontologica Sinica New Series D. No. 1: 1-180. 